\title{
The Regenerative Potential of bFGF in Dental Pulp Repair and Regeneration
}

\author{
Keyue Liu, Sijing Yu, Ling Ye and Bo Gao* \\ State Key Laboratory of Oral Diseases, National Clinical Research Center for Oral Diseases, West China Hospital of Stomatology, \\ Sichuan University, Chengdu, China
}

Regenerative endodontic therapy intends to induce the host's natural wound-healing process, which can restore the vitality, immunity, and sensitivity of the inflammatory or necrotic pulp tissue destroyed by infection or trauma. Myriads of growth factors are critical in the processes of pulp repair and regeneration. Among the key regulatory factors are the fibroblast growth factors, which have turned out to be the master regulators of both organogenesis and tissue homeostasis. Fibroblast growth factors, a family composed of 22 polypeptides, have been used in tissue repair and regeneration settings, in conditions as diverse as burns, ulcers, bone-related diseases, and spinal cord injuries. Meanwhile, in dentistry, the basic fibroblast growth factor is the most frequently investigated. Thereby, the aim of this review is 2-fold: 1) foremost, to explore the underlying mechanisms of the bFGF in dental pulp repair and regeneration and 2) in addition, to shed light on the potential

\section{OPEN ACCESS}

Edited by:

Q. Adam Ye,

Harvard Medical School,

United States

Reviewed by:

Xiaogang $\mathrm{Xu}$,

Zhejiang University, China

Wenguo Cui,

Shanghai Jiao Tong University, China

*Correspondence:

Bo Gao

gaob@scu.edu.cn

Specialty section: This article was submitted to Integrative and Regenerative

Pharmacology,

a section of the journal

Frontiers in Pharmacology

Received: 13 March 2021

Accepted: 22 June 2021

Published: 20 July 2021

Citation:

Liu K, Yu S, Ye L and Gao B (2021) The Regenerative Potential of bFGF in

Dental Pulp Repair and Regeneration.

Front. Pharmacol. 12:680209.

doi: 10.3389/fphar.2021.680209 therapeutic strategies of the bFGF in dental pulp-related clinical applications.

Keywords: fibroblast growth factors, basic fibroblast growth factor, regenerative endodontic therapy, regenerative endodontics, pulp repair, pulp regeneration

\section{INTRODUCTION}

With the advancement of our knowledge in pulp biology, the concept of treatment of endodontic diseases changes accordingly. "Regenerative endodontics" has been defined as "biologically based procedure designed to replace damaged structures, including dentin and root structures, as well as cells of the pulp-dentin complex" (Murray et al., 2007). The new era of regenerative endodontic therapy intends to induce the host's natural wound-healing process, which can restore the vitality, immunity, and sensitivity of the inflammatory or necrotic pulp tissue destroyed by infection or trauma (Yang et al., 2016).

Both pulp repair and regeneration processes are orchestrated by a highly coordinated interplay of different growth factors and cytokines (Orti et al., 2018). These myriads of growth factors create a favorable microenvironment conducive to tissue repair and/or regeneration taking place and act as signaling molecules that regulate cell behaviors, including migration, proliferation, and differentiation (Kim et al., 2018). Among the key regulatory factors are the fibroblast growth factors (FGFs), which have turned out to be the master regulators of both organogenesis and tissue homeostasis (Maddaluno et al., 2017). FGFs are a family of growth factors, consisting of 22 members that share $13-71 \%$ sequence homology in mammals (Ornitz and Itoh, 2001). Major attention has been paid to the use of FGFs in tissue repair and regeneration settings, in conditions as diverse as burns, ulcers, bone-related diseases, and spinal cord injuries, just to name a few (EL Agha et al., 2016; Nunes et al., 2016; Zhou et al., 2018; Wang J. et al., 2019). Meanwhile, in dentistry, the basic fibroblast growth factor (bFGF), also termed FGF-2, is the most frequently investigated (Vaseenon et al., 2020). As a member of the FGF family, the bFGF has been implicated as a signaling molecule that contributes to the regulation of virtually all aspects of tooth 


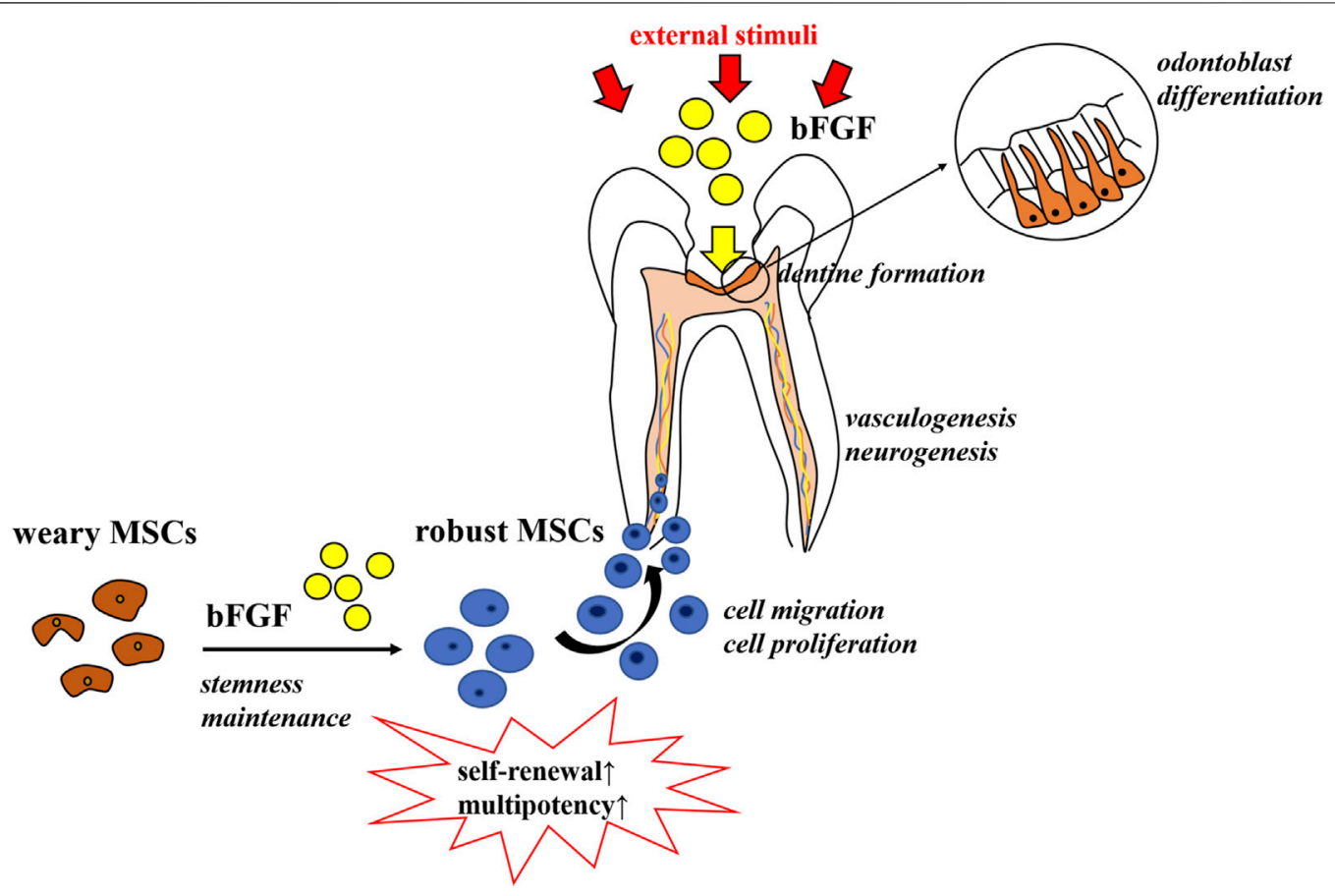

FIGURE 1 | Role of the bFGF in pulp repair and regeneration. The bFGF contributes to the regulation of virtually all aspects of tooth development, repair, and regeneration, including mesenchymal stem cells' stemness maintenance, migration, and proliferation, as well as dentine formation, vasculogenesis, and neurogenesis.

development, repair, and regeneration (Li et al., 2014; Vaseenon et al., 2020), including mesenchymal stem cell migration, proliferation, and stemness maintenance, as well as dentine formation, vasculogenesis, and neurogenesis (as shown in Figure 1) (Galler et al., 2012; Chang et al., 2017).

To figure out the role of the bFGF in regenerative endodontics, this review aims to give a comprehensive summary of the underlying mechanisms associated with the bFGF in promoting dental pulp repair and regeneration and shed light on the potential therapeutic strategies of the bFGF in dental pulp-related clinical applications.

\section{THE UNDERLYING MECHANISMS OF BASIC FIBROBLAST GROWTH FACTOR IN DENTAL PULP REPAIR AND REGENERATION}

According to the mode of action, the bFGF acts through binding to tyrosine kinase FGF receptors 1-4 (FGFR1-4) on the cell membrane (Müller et al., 2012). When the bFGF binds to its receptors, phosphorylation occurs and subsequently triggers a cascade of intracellular signaling pathways, such as the RASMAPK, PI3K-AKT, PLC $\gamma$, and JAK/STAT signaling pathways, initiating cell migration, proliferation, and differentiation (Müller et al., 2012). These findings lead to the hypothesis that the bFGF may use different intracellular signaling pathways to control specific biological processes in dental pulp repair and regeneration (Nowwarote et al., 2020). In this regard, we try to elucidate the potential roles of the bFGF in the specific biological processes, respectively.

\section{Cell Migration}

Before the regeneration occurs, cells must migrate to the sites where they are required to function (Adam and Richard, 1999). The migration process is initiated by more than 50 chemotactic factors which have been identified in mammals (Horuk, 2001). Among those chemotactic factors, the bFGF has been reported to induce the migration of certain types of mesenchymal stem cells (MSCs) which are critical for pulp regeneration, including adult dental pulp stem cells (DPSCs), stem cells from human exfoliated deciduous teeth (SHEDs), stem cells from apical papilla (SCAPs), bone marrow-derived mesenchymal stem cells (BMMSCs), and so on (Peng et al., 2009). Several cytokines were examined to enhance the migratory ability of BMMSCs, while the bFGF in particular was able to initiate the migration of BMMSCs in a dose-dependent manner via the Akt/protein kinase B (PKB) pathway (Schmidt et al., 2006). It was reported that low concentrations of the bFGF attracted BMMSCs, whereas higher concentrations resulted in an ambivalent effect (Schmidt et al., 2006). The ability of the bFGF to induce the migration of DPSCs was also verified (Howard et al., 2010), which agreed with the later study that reported that the bFGF significantly recruited more DPSCs seeded on the surface of 3D collagen gel cylinders into the deep (Suzuki et al., 2011). Coincidentally, Fayazi et al. claimed that the number of SCAPs recruited by the G-CSF and bFGF was approximately 2 -fold greater than that of other tested factors (Fayazi et al., 2017), and there was no apparent difference between the G-CSF and the bFGF in homing effect (Takeuchi et al., 2015). The periodontal ligament 
was also reported as a good source of MSCs (PDLSCs), which have a similar feature to that of BMMSCs and DPSCs, and could also contribute to the regenerative dentistry (Trubiani et al., 2008). In this regard, Zhang et al. verified that the bFGF promoted PDLSC migration and adhesion with more prominent ability than the VEGF (Zhang et al., 2013). Furthermore, the implantation of collagen scaffolds containing the bFGF resulted in abundant cell ingrowth, recellularization, and revascularization in endodontically treated root canals (Kim J. Y. et al., 2010).

Collectively, the bFGF is an efficacious chemotactic factor to facilitate the motility of MSCs and the following tissue remodeling processes, thereby providing a therapeutic basis for the cell homing strategy (Kim J. Y. et al., 2010; Galler et al., 2014).

\section{Cell Proliferation}

Generally, stem cell populations of various oral cells would dramatically decrease during the culture period (Min et al., 2011), which greatly limited their applications in tissue regeneration.

The mitogenic ability of the bFGF has attracted much attention. Morito et al. showed that the ratio of dental pulp cells in the S-phase and the ratio of hDPCs expressing STRO-1 were significantly higher when in the presence of the bFGF (Morito et al., 2009). The mitogenic effect of the bFGF on dental pulp cells was also supported recently by adding it in culture medium. Promising results were received in that the bFGF significantly promoted the proliferation of DPSCs through activating the ERK pathway without comprising cell stemness and pluripotency (Luo et al., 2021). With no exceptions, the mitogenic potential of the bFGF on SHEDs was also found (Sukarawan et al., 2014), and further study revealed that the bFGF promoted SHED colony-forming units via the FGFR/PI3K pathway (Nowwarote et al., 2020). In the gene level, the bFGF was reported to be in charge of controlling the cell cycle progression by significantly increasing the MKI67 mRNA and Ki67 protein level in SHEDs (Nowwarote et al., 2020) and regulating the cdc2 and cyclin B1 expression in HDPCs and SCAPs in a dosedependent manner via the MEK/ERK pathway (Chang et al., 2017; Chang et al., 2020), leading to a higher G2/M subpopulation and promoting the cell proliferation process (Nowwarote et al., 2020).

Taking those pieces of evidence together, the bFGF has the superiority to promote cell proliferation and control the cell cycle progression via stimulating the expression of related genes and proteins, including Ki67, cdc2, and cyclin B1. Therefore, its mitogenic effect can be put into use to amplify the cell number in order to obtain the sufficient amount of stem cells required for endodontic regenerative treatments and can also brighten the future of stem cell banking and tissue engineering (Luo et al., 2021).

\section{Stemness Maintenance}

Stemness maintenance has emerged to preserve the two defined features of stem cells, self-renewal and multipotency, which would become limited when these cells are introduced in longterm culture (Kong et al., 2019). Interestingly, the bFGF added in growth medium was proven to be able to support the self-renewal of human embryonic stem cells and maintain them in a multipotent state (Ehman et al., 2006; Diecke et al., 2008). In addition, the bFGF has also been demonstrated to maintain MSC potential in multilineage differentiation. Correspondingly, the bFGF, in low-density cultures, was reported to retain the osteogenic, adipogenic (Tsutsumi et al., 2001), and chondrogenic potential (Solchaga et al., 2005) of BMMSCs through the regulation of the MAPK and Wnt signaling pathways (Solchaga et al., 2005). Although the expression of mesenchymal stem cell markers was generally decreased during culture, treatment with the bFGF could delay their decrements and maintain their expressions in oral stem cells during culture (Lee et al., 2015). Additional studies demonstrated that the bFGF regulated stemness maintenance by increasing the gene expression of pluripotent stem cell markers including NANOG, OCT4, and REX1 on SCAPs, DPSCs, and SHEDs (Wu et al., 2012; Osathanon et al., 2011; Sukarawan et al., 2014). It was further revealed that the bFGF induced REX1 expression via the FGFR/Akt pathway with IL-6 as a middle regulator (Nowwarote et al., 2017).

Taken together, these investigations imply the important role of the bFGF in maintaining human stem cells' stemness, which is a critical step toward the clinical application of MSCs in regenerative endodontics.

\section{Dentinogenesis}

Once subjected to external injuries, the pulp cells may go through proliferation and differentiation, developing into odontoblastlike cells to elicit reparative dentinogenesis, which is critical for the pulpal wound-healing process (Yamamura, 1985). Dentinogenesis is a complex and multistep process, which is regulated by various growth factors including the bFGF (Cooper et al., 2010). However, the effects of the bFGF on mineralization and odontoblast differentiation remain elusive, while both stimulatory and inhibitory effects of the bFGF on dentinogenesis have been reported. Several studies have shown that the bFGF inhibited dentinogenesis and the expression of dentin sialophosphoprotein (Dspp) and alkaline phosphatase (ALP) (Tsuboi et al., 2003; Takedachi et al., 2009; Kim et al., 2014). On the other hand, other studies have shown that the bFGF stimulated the formation of osteodentin and the expression of Dspp and ALP (Kikuchi et al., 2007; Ishimatsu et al., 2009; Kim Y.-S. et al., 2010). Thus, to gain better insight into the biphasic role of the bFGF in dentinogenesis and cell differentiation in the odontoblast lineage, the underlying mechanisms of these controversial results need to be elaborated upon.

Dental pulp cells at different stages of odontoblast differentiation were identified by using a series of transgenic mice (Sagomonyants and Mina, 2014a). Studies have shown that 2.3-GFP and 3.6-GFP transgenes were activated at early stages of odontoblast differentiation (polarizing odontoblasts), and DMP1-GFP first emerged in functional/secretory odontoblasts. Meanwhile, all three transgenes (2.3-GFP, 3.6-GFP, and DMP1GFP) were expressed at high levels in fully differentiated/mature odontoblasts (Braut et al., 2003; Balic et al., 2010; Balic and Mina, 2011). In addition, researchers have generated a new kind of transgenic mouse using the bacterial artificial chromosome 
(BAC), directing the expression of the DSPP-Cerulean transgene that can be used to identify fully differentiated odontoblasts in the heterogeneous pulp cultures (Sagomonyants and Mina, 2014a). Cells were isolated and first grown for 7 days in medium supporting their proliferation (proliferation phase) and then for an additional 7 days in medium inducing their mineralization (differentiation/mineralization phase) (Sagomonyants and Mina, 2014b). Experiments conducted showed that the effects of the bFGF on odontogenic differentiation of pulp cells were stage-specific and depended on the stage of maturity of cells (Sagomonyants and Mina, 2014a). During the proliferation phase of in vitro growth, early and limited exposure to the bFGF increased the expression of the markers of dentinogenesis and the percentage of DMP1-GFP + functional odontoblasts, showing the differentiation of early progenitors into functional odontoblasts. During the mineralization/differentiation phase, additional/continuous exposure to the bFGF decreased the expression of the markers of dentinogenesis and the expression of DMP1-GFP and DSPPCerulean transgenes, indicating the shrinkage of the extent of mineralization and the failure of mature odontoblast differentiation. However, immediate withdrawal of bFGF for 7 days rapidly and mostly completed the recovery of mineralization and the expression of various GFP transgenes and dentinogenic markers (Sagomonyants and Mina, 2014a). Collectively, these results suggested a positive role of the bFGF in early differentiation into functional odontoblasts but a negative role in further differentiation into fully differentiated/mature odontoblasts.

Additional experiments were in progress to examine the underlying mechanisms mediating the biphasic effects of the bFGF on odontogenic differentiation. Studies revealed that the effects of the bFGF on odontoblast differentiation were mediated through the activation of FGFR/MEK/Erk1/2 signaling (Sagomonyants et al., 2015; Sagomonyants et al., 2017), and additional research examined that the BMP and Wnt signaling pathways also participated in the process (Sagomonyants and Mina, 2014b). Early and limited bFGF treatment promoting odontogenic differentiation during the proliferation phase was associated with increased levels of the components of the BMP (Bmp2, Dlx5, Msx2, and Osx) and Wnt (Wnt10a and Wisp2) pathways and with a decreased expression of the Wnt signaling inhibitor (Nkd2). Further addition of the bFGF suppressing the terminal odontogenic differentiation during the differentiation/ mineralization phase was accompanied by decreased expression of the components of the BMP signaling (Bmp2, Runx2, and Osx) and lower levels of Wnt inhibitors (Nkd2 and Dkk3) but increased expression of the Wnt signaling (Wnt10a). Taken together, these observations suggested that the BMP signaling could act as a positive regulator during odontoblast differentiation, while Wnt signaling stimulated early odontoblast differentiation but inhibited the terminal odontoblast differentiation (Sagomonyants et al., 2017). Furthermore, Vining et al. also revealed the possible mechanism of the early and limited exposure to the bFGF promoting odontogenic differentiation by expanding aSMAtdTomato $^{+}$cells and accelerating their differentiation into odontoblasts (Vining et al., 2018). IFT80 (intraflagellar transport protein 80 ) may also be involved in the positive differentiation process by maintaining cilia formation and FGFR1 expression and subsequently activating the AKT, Hh, and BMP2 signaling pathways to drive DPSCs differentiating into the odontogenic lineage (Yuan et al., 2019a). Nevertheless, the attenuation of ITGA11, CTGF, and ATF4 levels (Novais et al., 2019) and the downregulation of the Pi/PPi ratio (Nowwarote et al., 2018) in bFGF-treated SHEDs may participate in the negative regulatory mechanisms of the bFGF in odontogenic differentiation.

These observations together show the stage-specific effects of the bFGF on dentinogenesis through dental pulp cells (as shown in Figure 2) and provide a better insight into the treatments for vital pulp therapy and dentinal regeneration by priming the dental pulp tissue with the bFGF to achieve the desired mineralization state, which may be able to impede the excessive calcification in the pulp (Qian et al., 2015).

\section{Neurogenesis}

Neural regeneration is critical for ideal regenerative endodontic treatment so as to regain the normal sensation of the affected teeth (Kim et al., 2018). The bFGF is an important neurotrophin which possesses superior properties to promote neural stem cell (NSC) migration, proliferation, and self-renewal (Yeoh and de Haan, 2007). Ye et al. further informed that the bFGF could promote the survival and differentiation of NSCs to reduce brain damage and restore sensorimotor function after neonatal hypoxia-ischemia (Ye et al., 2018). The bFGF has also been reported to be able to maintain the survival of neuronal and glial cells, probably by protecting neurons from ROS-induced cell death and antagonizing the neuronal apoptosis induced by glutamate (Liu and Zhu, 1999). Indirectly, bFGF priming could protect cultured DPCs from hydrogen peroxide-induced cell death and increased the number of DPCs surviving so as to provide neurotrophic factors, thereby promoting axonal regeneration and locomotor function recovery (Nagashima et al., 2017).

DPSCs, deriving from the neural crest, retain remarkable characteristics that are similar to those of neural cells and have the potential to undergo neural differentiation to help crushed nerves achieve functional recovery and anatomical repair in vivo (Wang et al., 2020). The neurotrophic and neuroprotective merits of DPSCs make it an ideal stem cell source for neural repair and regeneration (Luo et al., 2018b; Wang D. et al., 2019). Accordingly, the implanted DPSCs could promote endogenous neural stem/progenitor cell proliferation, recruitment, and maturation through modulating the local microenvironment via secreting multiple factors, especially the bFGF (Huang et al., 2008). On the other hand, numerous protocols have documented that the exogeneous application of the bFGF could facilitate DPSCs differentiating into neurons. Studies discovered that the supplementation of the bFGF increased the neurosphere size and the neurogenic markers of DPSCs (Osathanon et al., 2011; Kang Y.-H. et al., 2019) and simultaneously revealed that the bFGF induced neuronal differentiation of DPSCs through the PLC $\gamma$ signaling pathway 


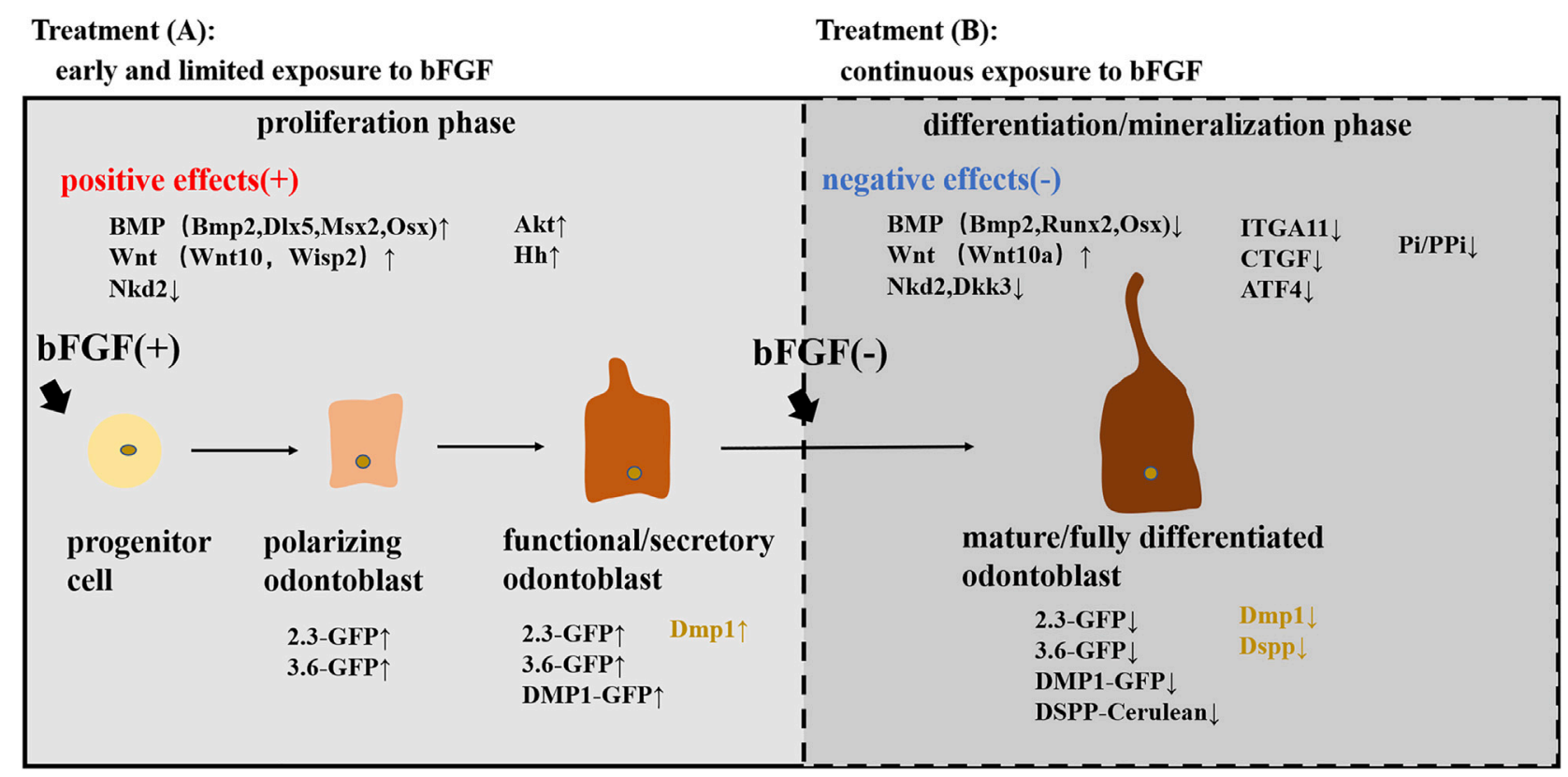

FIGURE 2 | Stage-specific effects of the bFGF on odontoblast differentiation. Treatment (A): early and limited exposure to the bFGF during the proliferation phase stimulated the differentiation into functional/secretory odontoblasts and increased the expression of various GFP transgenes (2.3-GFP, 3.6-GFP, and DMP1-GFP) and dentinogenic markers (Dmp1) by activating the BMP, Wnt, and Akt pathways. Treatment (B): continuous exposure to the bFGF during the differentiation/mineralization phase inhibited the differentiation into mature odontoblasts and decreased the expression of GFP transgenes (2.3-GFP, 3.6-GFP, and DSPP-Cerulean) and dentinogenic markers (Dmp1 and Dspp) by activating the Wnt pathway while suppressing the BMP pathway and downregulating ITGA11, CTGF, and ATF4 levels and the $\mathrm{Pi} / \mathrm{PPi}$ ratio.

(Osathanon et al., 2011). Meanwhile, Zheng et al. recognised the phospho-ERK ( $p$-ERK) activation as a major mediator in such a process (Zheng et al., 2020). In addition, the bFGF and NGF were shown to have a synergistic effect to increase neural differentiation of DPSCs by upregulating the levels of Sirt1 and activating the ERK and Akt signaling pathways (Zhang et al., 2017). Coincidentally, the bFGF and NGF-cotransfected BMMSCs were also inclined to differentiate into neurons with the manipulation of the ERK and Akt signaling pathways (Hu et al., 2016). In the preliminary study, it is noteworthy that when exogenously supplied with the bFGF, the CD81 and nestin double-positive dental pulp cells localized in the apical portion were deemed to be mainly responsible for the neural regeneration (Sasaki et al., 2008).

In summary, the results from the aforementioned studies emphasize the important role of the bFGF in neural differentiation and promise new therapeutic strategies by using the bFGF to treat neurological diseases and repair neuronal damage, such as spinal cord injury (SCI), Parkinson's disease, neonatal hypoxia-ischemia (NHI), and Alzheimer's disease (Barzilay et al., 2008; Zhang et al., 2014; Luo et al., 2018a; Ye et al., 2018). However, achieving the neurite growth in root canals with the treatment of the bFGF needs more experimental reports.

\section{Vasculogenesis/Angiogenesis}

Angiogenesis is important for tissue regeneration, especially for the dental pulp, since the nutrition of dental pulp could only be provided from the apical foramen of the tooth. The greatest challenge of tissue engineering the "pulp" is to achieve in vivo revascularization from the host blood supply (Wigler et al., 2013). The angiogenesis process refers to the migration, proliferation, and differentiation (tube formation) of vascular endothelial cells and is mediated by various angiogenic factors acting on endothelial cells and pericytes (mural cells) (Chung and Ferrara, 2011).

The bFGF was generally described as a protective factor that protects endothelial cells from the programmed cell death process (Karsan et al., 1997; Takeuchi et al., 2015) and was also recognized as one of the potent angiogenesis inducers that prompt vascular formation by stimulating the migration, proliferation, and differentiation of endothelial cells in a doseand time-dependent manner (Kanda et al., 1999; Kitamura et al., 2014; Zbinden et al., 2018). The angiogenic effect of the bFGF was evaluated similar to that of the VEGF when at the same dosage (Mullane et al., 2008).

DPSCs were shown to locate adjacent to vascular tubes assuming a pericyte location and have also been demonstrated to display potential pericyte-like topography and function. It was reported that the majority of DPSCs expressed the typical pericyte markers including alpha-smooth muscle actin ( $\alpha$-SMA), NG2, PDGFR $\beta$, CD146, and 3G5 (Nam et al., 2017). The pericyte-like properties of DPSCs were investigated to enhance angiogenesis by stabilizing the preexisting vessel-like structures formed by endothelial cells and increasing their longevity, leading to more mature tube-like structures' formation in vitro via the EphrinB2/EphB4 signaling pathway (Dissanayaka et al., 2012; 
Janebodin et al., 2013; Gong et al., 2019). Meanwhile, the bFGF treatment was able to augment the expression of NG2 and $\alpha$-SMA of DPSCs and finally, supported the stabilization of HUVEC tubes for a longer time (Delle et al., 2019). In addition, bFGF priming had a stronger impact on DPSCs than hypoxia and enhanced the proangiogenic effect of DPSCs through the secretion of the HGF (hepatocyte growth factor) and the VEGF (Gorin et al., 2016).

In conclusion, the bFGF is an angiogenic factor targeting endothelial cells directly and is capable of facilitating angiogenesis by enhancing the pericyte-like properties of DPSCs.

\section{Cytokine Production, Matrix Turnover, and Anti-Apoptosis}

Beyond that, available studies replenished the bFGF with the abilities of cytokine production, matrix turnover, and antiapoptosis.

It was stated that the bFGF enhanced dental pulp repair/ regeneration by upregulating the expression of several cytokines, including IL-6, IL-8, MCP-1, MIP-1 $\alpha$, and CCL20, via the PKC/ PI3K-AKT/MAPK signaling pathways. The bFGF-induced cytokines could trigger the innate cellular responses in dental pulp to promote cell differentiation and dentin formation (Kim Y.-S. et al., 2010).

The bFGF may also influence the extracellular matrix turnover through stimulating TIMP-1 expression in HDPCs and SCAPs (Chang et al., 2017; Chang et al., 2020) while inhibiting the expression of type I collagen and downregulating related genes in SHEDs (COL5A1, COL8A2, COL11A1, and COL15A1) and periodontal ligament stem/progenitor cells (COL1A1, COL3A1, ACTA2, and FBN1) (Nowwarote et al., 2020). The influence of the bFGF on collagen genes raised a hypothesis that the bFGF may act as an anti-fibrotic agent in several cell types (Grella et al., 2016). How the bFGF affects pulp repair and regeneration through matrix turnover awaits further investigation.

Besides, the bFGF was reputed to be a survival factor which inhibited cellular senescence and apoptosis in adipose-derived mesenchymal stromal cells (ASCs), probably by diminishing the expression of SA- $\beta$ gal, p21, and p53 (Nawrocka et al., 2017). A similar anti-apoptosis impact of the bFGF was also underscored when being applied to neural precursor cells (NPCs) (Mellisa and Kristi, 2006), indicating that the bFGF is a potential therapeutic agent in stem cell-based tissue regeneration, while the antisenescence and anti-apoptosis properties of the bFGF in dental stem cells need more elaboration.

\section{THE POTENTIAL THERAPEUTIC STRATEGIES OF BASIC FIBROBLAST GROWTH FACTOR IN PULP REPAIR AND REGENERATION}

The bFGF is certified for safe usage and has already been applied in the treatment of ulcer and burns (Akita et al., 2008). The bFGF has also contributed much to the field of nerve (Matsumine et al., 2016), muscle (Goto et al., 2020), and bone regeneration (Chen et al., 2011) based on its prominent regenerative potential. As mentioned above, the bFGF has combinatorial trophic effects on dental stem cells for pulp repair/regeneration to either induce cell migration, proliferation, and differentiation or regulate matrix turnover, cytokine production, and the apoptosis procedure. Therefore, the bFGF can be confirmed to be a safe and competent candidate for clinical applications in pulp regeneration therapy. To sustain this view, we collect the therapeutic protocols which have been developed to apply the bFGF in pulp repair and regeneration therapy.

The regenerative endodontic treatment (RET) contains two different clinical approaches. The first aims to achieve local pulpal regeneration and dentin bridge formation via pulp-capping agent usage to stimulate the healing process and preserve the pulp vitality (referred to as "pulp repair"). Another approach strives to induce the growth of new pulp-like tissue in the entire disinfected root canal space in order to revitalize the teeth (referred to as “pulp regeneration”) (Orti et al., 2018).

\section{Pulp Repair}

When the dental pulp is exposed to external stimuli such as caries infection or traumatic injuries, the preservation of dental pulp or the dentin-pulp complex and the maintenance of its viability are essential to avoid serious consequences such as tooth extraction (Kitamura et al., 2012). The formation of new dentin in the site of dentin defects is essential to the local regeneration of the dentinpulp complex (Kitamura et al., 2012).

For the pulp exposures, at the reversible stage, pulpal inflammation is treated using a direct pulp-capping technique. Calcium hydroxide and mineral trioxide aggregate (MTA) are widely used as pulp-capping materials due to their properties of mobilizing extracellular molecules which then initiate specific biological actions and promote dentin bridge formation (Graham et al., 2006; Li et al., 2015; Tomson et al., 2017; Torabinejad et al., 2018). However, the materials above have been criticized for their limited capacity in tissue regeneration (Chakka et al., 2020) and the tunnel defects in the formed dentin bridge (Chen et al., 2017). Moreover, the treatments elicit the formation of a thin layer of necrotic tissue underneath the capping material (de Souza Costa et al., 2008). Therefore, it is clear that in the future, pulp-capping procedures will rely on a more biological approach (Chakka et al., 2020). Promisingly, bFGF-loaded MesoCS nanoparticles have been shown to be capable of upregulating the odontogenicrelated protein of hDPCs (Huang et al., 2017). Following studies have correspondingly reported the local applications of the bFGF as a bioactive molecule that received promising results under the pulp exposure condition. Research has succeeded in treating the pulp exposure through combining the bFGF with the HAP nanoparticle-assembled powder (nano-HAP) and applying this compound to the exposed dental pulp of rat molars. Histological and radiological results showed that the application of the nano-HAP/bFGF induced the invasion of dental pulp cells and vessels, indicating the regeneration of pulp tissue, and stimulated the formation of a dentinal bridge containing numerous dentinal tubules (Imura et al., 2019). It was 

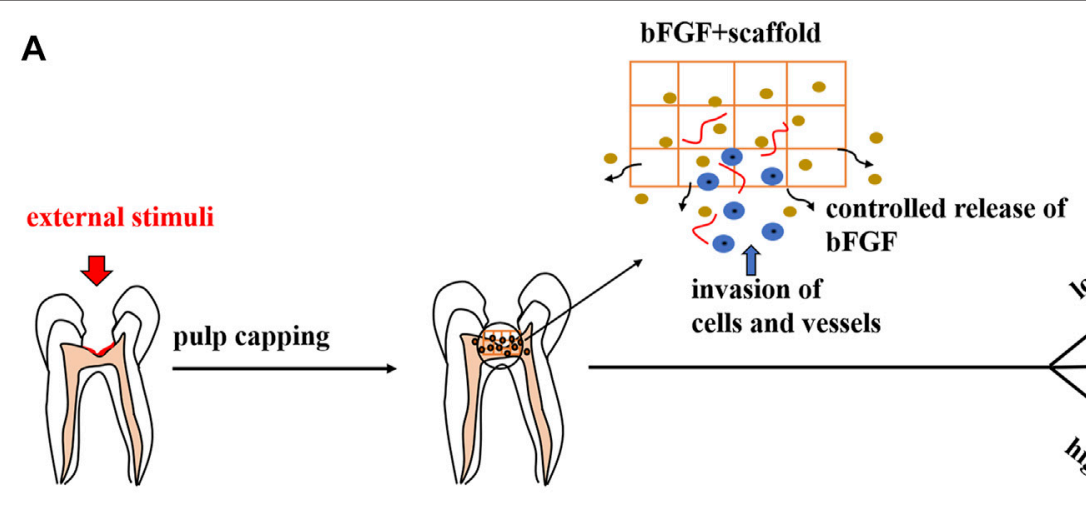

(a)

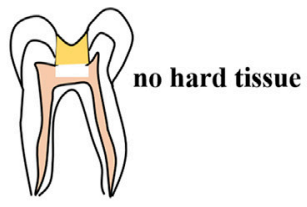

(b)

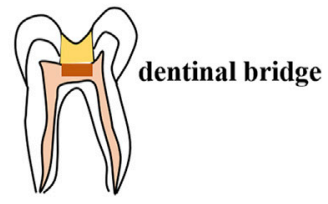

(c)

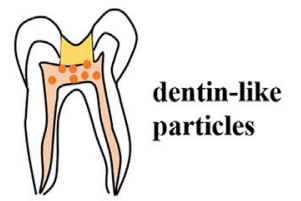

B

external stimuli (a)

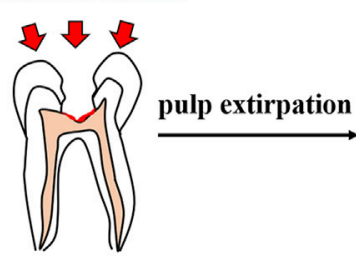

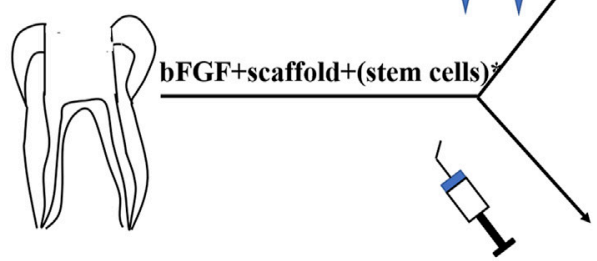

(b)

injectable

form
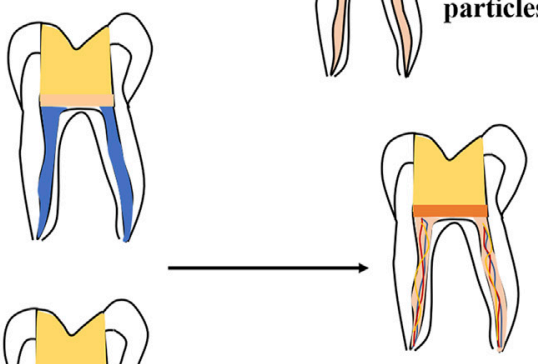

FIGURE 3 | Potential therapeutic strategies of the bFGF in regenerative endodontic therapy. (A) Pulp repair. The bFGF could be prepared as a pulp-capping agent when combined with a customized scaffold. This drug carrier system could provide controlled release of the bFGF and induce the ingrowth of cells and vessels, resulting in local pulp regeneration and dentine formation. The outcomes are dose-dependent: (a) low dose of the bFGF (0,0.05 mg/ml), no calcified tissue formation; (b) moderate dose of the bFGF (0.5 mg/ml), dentinal bridge-like structure on the dentin defect surface; and (c) high dose of the bFGF (1.0, $5.0 \mathrm{mg} / \mathrm{ml})$, dentin-like particles in the proliferating pulp. (B) Pulp regeneration. A specific scaffold in the gutta-percha point or an injectable form loads the bFGF or the combinatory group of factors, with or without stem cells, which could be applied in pulp regeneration therapy, leading to pulp-like tissue formation in root canals.

also validated that the appropriate dosage of the bFGF releasing from gelatin hydrogels could induce the formation of the dentinal bridge-like osteodentin on the surface of the regenerated pulp (Kitamura et al., 2012). The result with this perspective was in accordance with the report provided by Ishimatsu et al., who found that the structures of newly formed calcified tissue in the dentin defect were dependent on the dose of the bFGF incorporated in gelatin hydrogels (Ishimatsu et al., 2009). As far as the studies demonstrated, a high dose (1.0, $5.0 \mathrm{mg} / \mathrm{ml}$ ) of the bFGF induced calcified particles in the proliferating pulp, which was consistent with the previous results (Kikuchi et al., 2007), whereas a moderate dose $(0.5 \mathrm{mg} / \mathrm{ml})$ of the bFGF induced a dentinal bridge-like structure on the surface of the dentin defect. Meanwhile, at a low dose $(0,0.05 \mathrm{mg} / \mathrm{ml})$ of the bFGF, there was no calcified tissue formation (Ishimatsu et al., 2009) (as shown in Figure 3A).

Intriguingly, we find that all experimental models depicted above have used specific scaffolds as drug carriers to load the bFGF, including MesoCS nanoparticles, nano-HAP powder, and gelatin hydrogels, respectively. More scaffold materials can be established for pulp engineering, such as extracellular matrices, self-assembling peptides, and bio-ceramics (Galler et al., 2011). Research studies have shown that scaffold usage could provide sustained (controlled) release of the bFGF, avoiding a large usage of the bFGF protein because of its rapid release (Huang et al., 2017). Furthermore, the comparison of the free-bFGF with the loaded-bFGF was made by putting them into dentin defects above amputated pulp, and it was found that a noncontrolled release of the bFGF only accelerated reparative dentin formation in the residual dental pulp, whereas a controlled release of the bFGF from specific scaffolds induced the formation of DMP-1-positive and nestin-negative osteodentin in the pulp proliferating at the dentin defects, which indicated dentin regeneration (Ishimatsu et al., 2009; Kitamura et al., 2012).

As alluded to above, the application of a moderate dosage $(0.5 \mathrm{mg} / \mathrm{ml})$ of the bFGF with a specific scaffold as a drug carrier could induce local pulp regeneration and dentin bridge-like 
osteodentin formation, which is distinct from the conventional calcium hydroxide or mineral trioxide aggregate treatments. Considering the cost-effectiveness and the short half-life of the bFGF protein, a more current and efficient approach has been proposed to utilize gene-activated scaffolds for dental pulp capping. Chakka et al. transfected DPSCs with nanoplexes comprising polyethyleneimine (PEI) and plasmid DNA (pDNA) encoding for the bFGF and/or BMP-2. Loaded with collagen scaffolds, these nanoplexes resulted in increased expression of the bFGF and/or BMP-2 and enhanced the proliferation and mineralization properties of DPSCs (Chakka et al., 2020). This biological gene delivery approach in pulp capping is expected to facilitate a better pulp regeneration in vivo (Chakka et al., 2020).

\section{Pulp Regeneration}

When the external stimuli cause irreversible damage to dental pulp, the affected teeth can be traditionally treated with root canal therapy (RCT), which controls the infection while depriving the teeth of sensitivity and decreasing the resistance of the teeth because of pulp extirpation and malnutrition (Sjögren et al., 1990). In this situation, the pulp regeneration strategy is needed to regenerate a new vital tissue, which ideally mimics the dental pulp in order to extend the longevity of the teeth and improve the patients' life quality (Simon et al., 2011).

Appropriate cells (stem or progenitor cells), customized scaffolds, and appropriate signaling molecules are required for tissue engineering. Accordingly, this concept can be applied to dental pulp regeneration (Orti et al., 2018). Several reports have documented the regeneration of pulplike tissue in vitro via transplantation of dental pulp stem cells with scaffolds incorporating the bFGF. Self-assembling peptide nanofibers were fabricated to encapsulate dental pulp stem cells and growth factors, including the bFGF, TGF- $\beta 1$, and VEGF. Subcutaneous transplantation of the component within dentin cylinders into immunocompromised mice showed the formation of a vascularized soft connective tissue similar to dental pulp (Galler et al., 2012). In another approach, the combination of the bFGF and BMP-4 was mixed with DPSCs in a collagen scaffold and was transplanted into a special tissueengineering chamber. Newly formed tissue with blood vessel formation and DSPP-positive matrix production was later observed in this chamber (Srisuwan et al., 2012). A similar result was acquired in an ectopic root canal transplantation model in which the bFGF and DPSCs were packaged in a silk fibroin scaffold (Yang et al., 2015). It is also noteworthy that even without stem cell transplantation, the bFGF alone or with a combinatory group of growth factors could induce pulp regeneration due to their chemotactic properties. For example, the bFGF was shown to be able to yield recellularization and revascularization in endodontically treated human teeth which were implanted into the dorsum of rats (Suzuki et al., 2011). Meanwhile, the bFGF combined with a basal set of growth factors (NGF and BMP-7) also induced the regeneration of pulp-like tissue in the entire root canal from the root apex to the pulp chamber (Kim J. Y. et al., 2010). Thus, it is plausible to postulate a cell-free therapy which works by using selective chemotactic cytokines to recruit stem cells from residual pulp or from the periapical region and subsequently induce the regeneration of dental pulp. If this concept proved to be successful, cell-free therapy may be an advantageous approach that means a more reliable, feasible, and affordable alternative to the cell transplantation method (Galler et al., 2014). It is also thought-provoking that the bFGF was usually applied with a combination of other growth factors in the pulp regeneration therapy. These growth factors (like VEGF, BMP-2, and TGF- $\beta 1$ ) were said to have positive effects on pulp regeneration or proved to have a synergistic effect with the bFGF to enhance specific biological effects (He et al., 2008; Kang W. et al., 2019; Zhang et al., 2020). Other than the reciprocal growth factors, the supplementation of inorganic polyphosphate $[\operatorname{poly}(\mathrm{P})]$ was confirmed to facilitate the autocrine of the bFGF and enhance the function of the bFGF by promoting its stability and receptor affinity, resulting in the enhancement of the proliferation of HDPCs (Kawazoe et al., 2008). Intraflagellar transport protein 80 (IFT80) (Yuan et al., 2019b) and FGF-binding protein 1 (FGF-BP1) (Tassi et al., 2001) were also proposed as positive modulators in bFGF signal transduction. Therefore, future studies need to be carried out to understand the interplayed relationships among these key players and develop an optimal mixture of molecules for pulp regeneration (Schmalz et al., 2017). Besides, ongoing work is also required to determine whether the bFGF, a single cytokine, is sufficient for the regeneration of dental pulp (Kim J. Y. et al., 2010). For clinical concerns, Bhoj et al. took a first step to fabricate an RGD-bearing alginate scaffold that replicated the shape of gutta-percha. With the encapsulation of DPSCs and dual growth factors involving the bFGF and the VEGF, the customized RGD-bearing alginate framework could be simply shaped to fill the pulp space (Bhoj et al., 2015). In terms of future clinical application, scaffold materials could also be developed into an injectable form to achieve a more efficient root canal obtruration (Marler et al., 2000) (as shown in Figure 3B).

Collectively, these reports support that the bFGF is a validated candidate for future treatment in pulp regeneration.

\section{SUMMARY}

To sum up, the bFGF is known to be involved in all stages of pulp repair/regeneration and uses different intracellular signaling pathways to control specific biological processes, which may be determined by cell origins and treatment durations (Lee et al., 2015; Novais et al., 2019; Nowwarote et al., 2020). Abundant molecules and proteins are involved in such processes. In terms of clinical use, a moderate dose of the bFGF combined with a customized scaffold could be prepared as pulp-capping agents to preserve the vitality of the dentinepulp complex. Furthermore, the bFGF combined with stem cells and specific scaffolds is put into use in pulp regeneration therapy. In the near future, it is more advisable to begin a new paradigm in pulp regeneration with the cell-free approach (without exogeneous cell transplantation), cytokine reduction 
strategy (using only one or a minimum subset of cytokines), and injectable scaffold form (Kim J. Y. et al., 2010; Galler et al., 2011; Galler et al., 2014). At last, since the bFGF has attracted much attention in regenerative endodontic therapy, it is a wise choice to focus on its siblings. Not surprisingly, other FGFs, like FGF-8 (Tsikandelova et al., 2018), FGF-9 (Dai et al., 2012), and aFGF in particular (Cam et al., 1992; Li and Sae-Lim, 2007), are confirmed to own non-negligible regenerative potential in dentistry and tissue engineering. Therefore, greater effort should be put forward to exploit more regenerative properties of FGFs to reinforce their role in pulp repair and regeneration.

\section{REFERENCES}

Adam, J. S., and Richard, A. F. C. (1999). Cutaneous Woung Healing. N. Engl. J. Med. 341, 738-746. doi:10.1056/NEJM199909023411006

Akita, S., Akino, K., Imaizumi, T., and Hirano, A. (2008). Basic Fibroblast Growth Factor Accelerates and Improves Second-Degree Burn Wound Healing. Wound Repair Regen. 16, 635-641. doi:10.1111/j.1524-475X.2008.00414.x

Balic, A., Aguila, H. L., and Mina, M. (2010). Identification of Cells at Early and Late Stages of Polarization during Odontoblast Differentiation Using pOBCol3.6GFP and pOBCol2.3GFP Transgenic Mice. Bone 47, 948-958. doi:10.1016/j.bone.2010.08.009

Balic, A., and Mina, M. (2011). Identification of Secretory Odontoblasts Using DMP1-GFP Transgenic Mice. Bone 48, 927-937. doi:10.1016/ j.bone.2010.12.008

Barzilay, R., Kan, I., Ben-Zur, T., Bulvik, S., Melamed, E., and Offen, D. (2008). Induction of Human Mesenchymal Stem Cells into Dopamine-Producing Cells with Different Differentiation Protocols. Stem Cell Dev. 17, 547-554. doi:10.1089/scd.2007.0172

Bhoj, M., Zhang, C., and Green, D. W. (2015). A First Step in De Novo Synthesis of a Living Pulp Tissue Replacement Using Dental Pulp MSCs and Tissue Growth Factors, Encapsulated within a Bioinspired Alginate Hydrogel. J. Endodontics 41, 1100-1107. doi:10.1016/j.joen.2015.03.006

Braut, A., Kollar, E. J., and Mina, M. (2003). Analysis of the Odontogenic and Osteogenic Potentials of Dental Pulp In Vivo Using a Colla1-2.3-GFP Transgene. Int. J. Dev. Biol. 47, 281-292. doi:10.1387/ijdb.12755333

Cam, Y., Neumann, M. R., Oliver, L., Raulais, D., Janet, T., and Ruch, J. V. (1992). Immunolocalization of Acidic and Basic Fibroblast Growth Factors during Mouse Odontogenesis. Int. J. Dev. Biol. 36, 381-389. doi:10.1387/ ijdb. 1280156

Chakka, L. R. J., Vislisel, J., Vidal, C. d. M. P., Biz, M. T., Salem, A., Cavalcanti, B. N., et al. (2020). Application of BMP-2/FGF-2 Gene-Activated Scaffolds for Dental Pulp Capping. Clin. Oral Invest. 24, 4427-4437. doi:10.1007/s00784020-03308-2

Chang, M.-C., Chen, C.-Y., Chang, Y.-C., Zhong, B.-H., Wang, Y.-L., Yeung, S.-Y., et al. (2020). Effect of bFGF on the Growth and Matrix Turnover of Stem Cells from Human Apical Papilla: Role of MEK/ERK Signaling. J. Formos. Med. Assoc. 119, 1666-1672. doi:10.1016/j.jfma.2019.12.013

Chang, Y.-C., Chang, M.-C., Chen, Y.-J., Liou, J.-U., Chang, H.-H., Huang, W.-L., et al. (2017). Basic Fibroblast Growth Factor Regulates Gene and Protein Expression Related to Proliferation, Differentiation, and Matrix Production of Human Dental Pulp Cells. J. Endodontics 43, 936-942. doi:10.1016/ j.joen.2017.01.024

Chen, J., Cui, C., Qiao, X., Yang, B., Yu, M., Guo, W., et al. (2017). Treated Dentin Matrix Paste as a Novel Pulp Capping Agent for Dentin Regeneration. J. Tissue Eng. Regen. Med. 11, 3428-3436. doi:10.1002/term.2256

Chen, M., Song, K., Rao, N., Huang, M., Huang, Z., and Cao, Y. (2011). Roles of Exogenously Regulated bFGF Expression in Angiogenesis and Bone Regeneration in Rat Calvarial Defects. Int. J. Mol. Med. 27, 545-553. doi:10.3892/ijmm.2011.619

Chung, A. S., and Ferrara, N. (2011). Developmental and Pathological Angiogenesis. Annu. Rev. Cel Dev. Biol 27, 563-584. doi:10.1146/annurevcellbio-092910-154002

\section{AUTHOR CONTRIBUTIONS}

KL and SY conceived and drafted the original article. LY and BG instructed with regard to and reviewed the article. All authors approved the final article.

\section{FUNDING}

This work was supported by the Department of Science and Technology of Sichuan Province (CN) (Grant no. 2020YFS0202).

Cooper, P. R., Takahashi, Y., Graham, L. W., Simon, S., Imazato, S., and Smith, A. J. (2010). Inflammation-regeneration Interplay in the Dentine-Pulp Complex. J. Dentistry 38, 687-697. doi:10.1016/j.jdent.2010.05.016

Dai, J., Wang, J., Lu, J., Zou, D., Sun, H., Dong, Y., et al. (2012). The Effect of Coculturing Costal Chondrocytes and Dental Pulp Stem Cells Combined with Exogenous FGF9 Protein on Chondrogenesis and Ossification in Engineered Cartilage. Biomaterials 33, 7699-7711. doi:10.1016/j.biomaterials.2012.07.020

de Souza Costa, C. A., Duarte, P. T., de Souza, P. P., Giro, E. M. A., and Hebling, J. (2008). Cytotoxic Effects and Pulpal Response Caused by a mineral Trioxide Aggregate Formulation and Calcium Hydroxide. Am. J. Dent. 21, 255-261.

Delle, M. S., Martellucci, S., Clementi, L., Pulcini, F., Santilli, F., Mei, C., et al. (2019). In Vitro Conditioning Determines Capacity Dental Pulp Stem Cell Funct. as Pericyte-Like Cell Stem Cell Dev. 28, 695-706. doi:10.1089/scd.2018.0192

Diecke, S., Quiroga-Negreira, A., Redmer, T., and Besser, D. (2008). FGF2 Signaling in Mouse Embryonic Fibroblasts Is Crucial for Self-Renewal of Embryonic Stem Cells. Cells Tissues Organs 188, 52-61. doi:10.1159/000121282

Dissanayaka, W. L., Zhan, X., Zhang, C., Hargreaves, K. M., Jin, L., and Tong, E. H. Y. (2012). Coculture of Dental Pulp Stem Cells with Endothelial Cells Enhances Osteo-/Odontogenic and Angiogenic Potential In Vitro. J. Endodontics 38, 454-463. doi:10.1016/j.joen.2011.12.024

Ehman, E. C., Johnson, G. B., Villanueva-meyer, J. E., Cha, S., Leynes, A. P., Eric, P., and et al (2006). Basic FGF Support of Human Embryonic Stem Cell SelfRenewal. Stem Cells. 24, 568-574. doi:10.1634/stemcells.2005-0247

El Agha, E., Kosanovic, D., Schermuly, R. T., and Bellusci, S. (2016). Role of Fibroblast Growth Factors in Organ Regeneration and Repair. Semin. Cel Dev. Biol. 53, 76-84. doi:10.1016/j.semcdb.2015.10.009

Fayazi, S., Takimoto, K., and Diogenes, A. (2017). Comparative Evaluation of Chemotactic Factor Effect on Migration and Differentiation of Stem Cells of the Apical Papilla. J. Endodontics 43, 1288-1293. doi:10.1016/j.joen.2017.03.012

Galler, K. M., D’Souza, R. N., Hartgerink, J. D., and Schmalz, G. (2011). Scaffolds for Dental Pulp Tissue Engineering. Adv. Dent Res. 23, 333-339. doi:10.1177/ 0022034511405326

Galler, K. M., Eidt, A., and Schmalz, G. (2014). Cell-free Approaches for Dental Pulp Tissue Engineering. J. Endodontics 40, S41-S45. doi:10.1016/ j.joen.2014.01.014

Galler, K. M., Hartgerink, J. D., Cavender, A. C., Schmalz, G., and D’Souza, R. N. (2012). A Customized Self-Assembling Peptide Hydrogel for Dental Pulp Tissue Engineering. Tissue Eng. A 18, 176-184. doi:10.1089/ten.tea.2011.0222

Gong, T., Xu, J., Heng, B., Qiu, S., Yi, B., Han, Y., et al. (2019). EphrinB2/EphB4 Signaling Regulates DPSCs to Induce Sprouting Angiogenesis of Endothelial Cells. J. Dent Res. 98, 803-812. doi:10.1177/0022034519843886

Gorin, C., Rochefort, G. S., Bascetin, R., Ying, H., Lesieur, J., Sadoine, J., and et al (2016). Priming Dental Pulp Stem Cells with Fibroblast Growth Factor-2 Increases Angiogenesis of Implanted Tissue-Engineered Constructs through Hepatocyte Growth Factor and Vascular Endothelial Growth Factor Secretion. Stem Cell Transl. Med. 5, 392-404.

Goto, T., Ueha, R., Sato, T., Fujimaki, Y., Nito, T., and Yamasoba, T. (2020). Single, High-dose Local Injection of bFGF Improves Thyroarytenoid Muscle Atrophy after Paralysis. The Laryngoscope 130, 159-165. doi:10.1002/lary.27887

Graham, L., Cooper, P. R., Cassidy, N., Nor, J. E., Sloan, A. J., and Smith, A. J. (2006). The Effect of Calcium Hydroxide on Solubilisation of Bio-Active Dentine Matrix Components. Biomaterials 27, 2865-2873. doi:10.1016/ j.biomaterials.2005.12.020 
Grella, A., Kole, D., Holmes, W., and Dominko, T. (2016). FGF2 Overrides TGF $\beta 1$ Driven Integrin ITGA11 Expression in Human Dermal Fibroblasts. J. Cel. Biochem. 117, 1000-1008. doi:10.1002/jcb.25386

He, H., Yu, J., Liu, Y., Lu, S., Liu, H., Shi, J., et al. (2008). Effects of FGF2 and TGF $\beta 1$ on the Differentiation of Human Dental Pulp Stem Cells In Vitro. Cel Biol. Int. 32, 827-834. doi:10.1016/j.cellbi.2008.03.013

Horuk, R. (2001). Chemokine Receptors. Cytokine Growth Factor. Rev. 12, 313-335. doi:10.1016/S1359-6101(01)00014-4

Howard, C., Murray, P. E., and Namerow, K. N. (2010). Dental Pulp Stem Cell Migration. J. Endodontics 36, 1963-1966. doi:10.1016/j.joen.2010.08.046

Hu, Y., Zhang, Y., Tian, K., Xun, C., Wang, S., and Lv, D. (2016). Effects of Nerve Growth Factor and Basic Fibroblast Growth Factor Dual Gene Modification on Rat Bone Marrow Mesenchymal Stem Cell Differentiation into Neuron-like Cells In Vitro. MOLECULAR MEDICINE REPORTS. 13, 49-58. doi:10.3892/ mmr.2015.4553

Huang, A. H.-C., Snyder, B. R., Cheng, P.-H., and Chan, A. W. S. (2008). Putative Dental Pulp-Derived Stem/Stromal Cells Promote Proliferation and Differentiation of Endogenous Neural Cells in the Hippocampus of Mice. Stem Cells 26, 2654-2663. doi:10.1634/stemcells.2008-0285

Huang, C.-Y., Huang, T.-H., Kao, C.-T., Wu, Y.-H., Chen, W.-C., and Shie, M.-Y. (2017). Mesoporous Calcium Silicate Nanoparticles with Drug Delivery and Odontogenesis Properties. J. Endodontics 43, 69-76. doi:10.1016/ j.joen.2016.09.012

Imura, K., Hashimoto, Y., Okada, M., Yoshikawa, K., and Yamamoto, K. (2019). Application of Hydroxyapatite Nanoparticle-Assembled Powder Using Basic Fibroblast Growth Factor as a Pulp-Capping Agent. Dent. Mater. J. 38, 713-720. doi:10.4012/dmj.2018-198

Ishimatsu, H., Kitamura, C., Morotomi, T., Tabata, Y., Nishihara, T., Chen, K.-K., et al. (2009). Formation of Dentinal Bridge on Surface of Regenerated Dental Pulp in Dentin Defects by Controlled Release of Fibroblast Growth Factor-2 from Gelatin Hydrogels. J. Endodontics 35, 858-865. doi:10.1016/ j.joen.2009.03.049

Janebodin, K., Zeng, Y., Buranaphatthana, W., Ieronimakis, N., and Reyes, M. (2013). VEGFR2-dependent Angiogenic Capacity of Pericyte-like Dental Pulp Stem Cells. J. Dent Res. 92, 524-531. doi:10.1177/0022034513485599

Kanda, S., Tomasini-Johansson, B., Klint, P., Dixelius, J., Rubin, K., and ClaessonWelsh, L. (1999). Signaling via Fibroblast Growth Factor Receptor-1 Is Dependent on Extracellular Matrix in Capillary Endothelial Cell Differentiation. Exp. Cel Res. 248, 203-213. doi:10.1006/excr.1999.4400

Kang, W., Liang, Q., Du, L., Shang, L., Wang, T., and Ge, S. (2019a). Sequential Application of bFGF and BMP-2 Facilitates Osteogenic Differentiation of Human Periodontal Ligament Stem Cells. J. Periodontal Res. 54, 424-434. doi:10.1111/jre.12644

Kang, Y.-H., Shivakumar, S. B., Son, Y.-B., Bharti, D., Jang, S.-J., Heo, K.-S., et al. (2019b). Comparative Analysis of Three Different Protocols for Cholinergic Neuron Differentiation In Vitro Using Mesenchymal Stem Cells from Human Dental Pulp. Anim. Cell Syst. 23, 275-287. doi:10.1080/19768354.2019.1626280

Karsan, A., Yee, E., Poirier, G. G., Zhou, P., Craig, R., and Harlan, J. M. (1997). Fibroblast Growth Factor-2 Inhibits Endothelial Cell Apoptosis by Bcl- 2dependent and Independent Mechanisms. Am. J. Pathol. 151, 1775-1784.

Kawazoe, Y., Katoh, S., Onodera, Y., Kohgo, T., Shindoh, M., and Shiba, T. (2008). Activation of the FGF Signaling Pathway and Subsequent Induction of Mesenchymal Stem Cell Differentiation by Inorganic Polyphosphate. Int. J. Biol. Sci. 4, 37-47. doi:10.7150/ijbs.4.37

Kikuchi, N., Kitamura, C., Morotomi, T., Inuyama, Y., Ishimatsu, H., Tabata, Y., et al. (2007). Formation of Dentin-like Particles in Dentin Defects above Exposed Pulp by Controlled Release of Fibroblast Growth Factor 2 from Gelatin Hydrogels. J. Endodontics 33, 1198-1202. doi:10.1016/j.joen.2007.07.025

Kim, J., Park, J.-C., Kim, S.-H., Im, G.-I., Kim, B.-S., Lee, J.-B., et al. (2014). Treatment of FGF-2 on Stem Cells from Inflamed Dental Pulp Tissue from Human Deciduous Teeth. Oral Dis. 20, 191-204. doi:10.1111/odi.12089

Kim, J. Y., Xin, X., Moioli, E. K., Chung, J., Lee, C. H., Chen, M., et al. (2010a). Regeneration of Dental-pulp-like Tissue by Chemotaxis-Induced Cell Homing. Tissue Eng. Part A 16, 3023-3031. doi:10.1089/ten.tea.2010.0181

Kim, S. G., Malek, M., Sigurdsson, A., Lin, L. M., and Kahler, B. (2018). Regenerative Endodontics: a Comprehensive Review. Int. Endod. J. 51, 1367-1388. doi:10.1111/iej.12954
Kim, Y.-S., Min, K.-S., Jeong, D.-H., Jang, J.-H., Kim, H.-W., and Kim, E.-C. (2010b). Effects of Fibroblast Growth Factor-2 on the Expression and Regulation of Chemokines in Human Dental Pulp Cells. J. Endodontics 36, 1824-1830. doi:10.1016/j.joen.2010.08.020

Kitamura, C., Nishihara, T., Terashita, M., Tabata, Y., and Washio, A. (2012). Local Regeneration of Dentin-Pulp Complex Using Controlled Release of FGF-2 and Naturally Derived Sponge-like Scaffolds. Int. J. Dentistry 2012, 1-8. doi:10.1155/2012/190561

Kitamura, N., Hasebe, T., Matsumoto, T., Hotta, A., Suzuki, T., Yamagami, T., et al. (2014). Basic Fibroblast Growth Factor as a Potential Stent Coating Material Inducing Endothelial Cell Proliferation. Jat 21, 477-485. doi:10.5551/jat.20404

Kong, Y., Ma, B., Liu, F., Chen, D., Zhang, S., Duan, J., et al. (2019). Cellular Stemness Maintenance of Human Adipose-Derived Stem Cells on $\mathrm{ZnO}$ Nanorod Arrays. Small 15, 1-11. doi:10.1002/smll.201904099

Lee, T.-H., Kim, W.-T., Ryu, C. J., and Jang, Y.-J. (2015). Optimization of Treatment with Recombinant FGF-2 for Proliferation and Differentiation of Human Dental Stem Cells, Mesenchymal Stem Cells, and Osteoblasts. Biochem. Cel Biol. 93, 298-305. doi:10.1139/bcb-2014-0140

Li, C.-Y., Prochazka, J., Goodwin, A. F., and Klein, O. D. (2014). Fibroblast Growth Factor Signaling in Mammalian Tooth Development. Odontology 102, 1-13. doi:10.1007/s10266-013-0142-1

Li, Z., Cao, L., Fan, M., and Xu, Q. (2015). Direct Pulp Capping with Calcium Hydroxide or Mineral Trioxide Aggregate: A Meta-Analysis. J. Endod. 41, 1412-1417. doi:10.1016/j.joen.2015.04.012

Li, Z., and Sae-Lim, V. (2007). Comparison of Acidic Fibroblast Growth Factor on Collagen Carrier with Calcium Hydroxide as Pulp Capping Agents in Monkeys. Dent Traumatol. 23, 278-286. doi:10.1111/j.1600-9657.2006.00459.x

Liu, X., and Zhu, X. (1999). Roles of P53, C-Myc, Bcl-2, Bax and Caspases in Glutamate-Induced Neuronal Apoptosis and the Possible Neuroprotective Mechanism of Basic Fibroblast Growth Factor. Mol. Brain Res. 71, 210-216. doi:10.1016/s0169-328x(99)00186-2

Luo, L., Albashari, A. A., Wang, X., Jin, L., Zhang, Y., Zheng, L., et al. (2018a). Effects of Transplanted Heparin-Poloxamer Hydrogel Combining Dental Pulp Stem Cells and bFGF on Spinal Cord Injury Repair. Stem Cell Int. 2018, 1-13. doi:10.1155/2018/2398521

Luo, L., He, Y., Wang, X., Key, B., Lee, B. H., Li, H., et al. (2018b). Potential Roles of Dental Pulp Stem Cells in Neural Regeneration and Repair. Stem Cell Int. 2018, 1-15. doi:10.1155/2018/1731289

Luo, L., Zhang, Y., Chen, H., Hu, F., Wang, X., Xing, Z., et al. (2021). Effects and Mechanisms of Basic Fibroblast Growth Factor on the Proliferation and Regenerative Profiles of Cryopreserved Dental Pulp Stem Cells. Cell Prolif 54, 1-12. doi:10.1111/cpr.12969

Maddaluno, L., Urwyler, C., and Werner, S. (2017). Fibroblast Growth Factors: Key Players in Regeneration and Tissue Repair. Dev. 144, 4047-4060. doi:10.1242/ dev. 152587

Marler, J. J., Guha, A., Rowley, J., Koka, R., Mooney, D., Upton, J., et al. (20002049-2058). Soft-Tissue Augmentation with Injectable Alginate and Syngeneic Fibroblasts. Plast. Reconstr. Surg. 105, 2049-2058. doi:10.1097/ 00006534-200005000-00020

Matsumine, H., Sasaki, R., Tabata, Y., Matsui, M., Yamato, M., Okano, T., et al. (2016). Facial Nerve Regeneration Using Basic Fibroblast Growth FactorImpregnated Gelatin Microspheres in a Rat Model. J. Tissue Eng. Regen. Med. 10, E559-E567. doi:10.1002/term.1884

Melissa, J. M., and Kristi, S. A. (2006). Contrasting Effects of Collagen and bFGF-2 on Neural Cell Function in Degradable Synthetic PEG Hydrogels. Wiley Intersci. 81, 269-278. doi:10.1002/jbm.a.30970

Min, J.-H., Ko, S.-Y., Cho, Y.-B., Ryu, C.-J., and Jang, Y.-J. (2011). Dentinogenic Potential of Human Adult Dental Pulp Cells during the Extended Primary Culture. Hum. Cel 24, 43-50. doi:10.1007/s13577-011-0010-7

Morito, A., Kida, Y., Suzuki, K., Inoue, K., Kuroda, N., Gomi, K., et al. (2009). Effects of Basic Fibroblast Growth Factor on the Development of the Stem Cell Properties of Human Dental Pulp Cells. Arch. Histology Cytol. 72, 51-64. doi:10.1679/aohc.72.51

Mullane, E. M., Dong, Z., Sedgley, C. M., Hu, J. C. C., Botero, T. M., Holland, G. R., and et al (2008). Effects of VEGF and FGF2 on the Revascularization of Severed Human Dental Pulps. J. Dent. Res. 87, 1144-1148. doi:10.1177/ 154405910808701204 
Müller, A.-K., Meyer, M., and Werner, S. (2012). The Roles of Receptor Tyrosine Kinases and Their Ligands in the Wound Repair Process. Semin. Cel Dev. Biol. 23, 963-970. doi:10.1016/j.semcdb.2012.09.015

Murray, P. E., Garcia-Godoy, F., and Hargreaves, K. M. (2007). Regenerative Endodontics: A Review of Current Status and a Call for Action. J. Endodontics 33, 377-390. doi:10.1016/j.joen.2006.09.013

Nagashima, K., Miwa, T., Soumiya, H., Ushiro, D., Takeda-Kawaguchi, T., Tamaoki, N., et al. (2017). Priming with FGF2 Stimulates Human Dental Pulp Cells to Promote Axonal Regeneration and Locomotor Function Recovery after Spinal Cord Injury. Sci. Rep. 7, 1-12. doi:10.1038/s41598-017-13373-5

Nam, H., Kim, G.-H., Bae, Y.-K., Jeong, D.-E., Joo, K.-M., Lee, K., et al. (2017). Angiogenic Capacity of Dental Pulp Stem Cell Regulated by SDF-1a-CXCR4 Axis. Stem Cell Int. 2017, 1-10. doi:10.1155/2017/8085462

Nawrocka, D., Kornicka, K., Szydlarska, J., and Marycz, K. (2017). Basic Fibroblast Growth Factor Inhibits Apoptosis and Promotes Proliferation of AdiposeDerived Mesenchymal Stromal Cells Isolated from Patients with Type 2 Diabetes by Reducing Cellular Oxidative Stress. Oxidative Med. Cell Longevity 2017, 1-22. doi:10.1155/2017/3027109

Novais, A., Lesieur, J., Sadoine, J., Slimani, L., Baroukh, B., Saubaméa, B., et al. (2019). Priming Dental Pulp Stem Cells from Human Exfoliated Deciduous Teeth with Fibroblast Growth Factor-2 Enhances Mineralization within TissueEngineered Constructs Implanted in Craniofacial Bone Defects. STEM CELLS Translational Med. 8, 844-857. doi:10.1002/sctm.18-0182

Nowwarote, N., Manokawinchoke, J., Kanjana, K., Fournier, B. P. J., Sukarawan, W., and Osathanon, T. (2020). Transcriptome Analysis of Basic Fibroblast Growth Factor Treated Stem Cells Isolated from Human Exfoliated Deciduous Teeth. Heliyon 6, e04246. doi:10.1016/j.heliyon.2020.e04246

Nowwarote, N., Sukarawan, W., Pavasant, P., Foster, B. L., and Osathanon, T. (2018). Basic Fibroblast Growth Factor Regulates Phosphate/pyrophosphate Regulatory Genes in Stem Cells Isolated from Human Exfoliated Deciduous Teeth. Stem Cel Res Ther 9, 1-14. doi:10.1186/s13287-018-1093-9

Nowwarote, N., Sukarawan, W., Pavasant, P., and Osathanon, T. (2017). Basic Fibroblast Growth Factor Regulates REX1 Expression via IL-6 in Stem Cells Isolated from Human Exfoliated Deciduous Teeth. J. Cel. Biochem. 118, 1480-1488. doi:10.1002/jcb.25807

Nunes, Q. M., Li, Y., Sun, C., Kinnunen, T. K., and Fernig, D. G. (2016). Fibroblast Growth Factors as Tissue Repair and Regeneration Therapeutics. PeerJ. 4, e1535. doi:10.7717/peer.1535

Ornitz, D. M., and Itoh, N. (2001). Fibroblast Growth Factors. Genome Biol. 2. doi:10.1186/gb-2001-2-3-reviews3005REVIEWS3005

Orti, V., Collart-Dutilleul, P.-Y., Piglionico, S., Pall, O., Cuisinier, F., and Panayotov, I. (2018). Pulp Regeneration Concepts for Nonvital Teeth: From Tissue Engineering to Clinical Approaches. Tissue Eng. B: Rev. 24, 419-442. doi:10.1089/ten.teb.2018.0073

Osathanon, T., Nowwarote, N., and Pavasant, P. (2011). Basic Fibroblast Growth Factor Inhibits Mineralization but Induces Neuronal Differentiation by Human Dental Pulp Stem Cells through a FGFR and PLC $\gamma$ Signaling Pathway. J. Cel. Biochem. 112, 1807-1816. doi:10.1002/jcb.23097

Peng, L., Ye, L., and Zhou, X. D. (2009). Mesenchymal Stem Cell Tooth Eng. Int J Oral Sci. 1, 6-12. doi:10.4248/ijos.08032

Qian, J., Jiayuan, W., Wenkai, J., Peina, W., Ansheng, Z., Shukai, S., et al. (2015). Basic Fibroblastic Growth Factor Affects the Osteogenic Differentiation of Dental Pulp Stem Cells in a Treatment-dependent Manner. Int. Endod. J. 48, 690-700. doi:10.1111/iej.12368

Sagomonyants, K., Kalajzic, I., Maye, P., and Mina, M. (2015). Enhanced Dentinogenesis of Pulp Progenitors by Early Exposure to FGF2. J. Dent Res. 94, 1582-1590. doi:10.1177/0022034515599768

Sagomonyants, K., Kalajzic, I., Maye, P., and Mina, M. (2017). FGF Signaling Prevents the Terminal Differentiation of Odontoblasts. J. Dent Res. 96, 663-670. doi:10.1177/0022034517691732

Sagomonyants, K., and Mina, M. (2014b). Biphasic Effects of FGF2 on Odontoblast Differentiation Involve Changes in the BMP and Wnt Signaling Pathways. Connect. Tissue Res. 55, 53-56. doi:10.3109/03008207.2014.923867

Sagomonyants, K., and Mina, M. (2014a). Stage-Specific Effects of Fibroblast Growth Factor 2 on the Differentiation of Dental Pulp Cells. Cells Tissues Organs 199, 311-328. doi:10.1159/000371343
Sasaki, R., Aoki, S., Yamato, M., Uchiyama, H., Wada, K., Okano, T., et al. (2008). Neurosphere Generation from Dental Pulp of Adult Rat Incisor. Eur. J. Neurosci. 27, 538-548. doi:10.1111/j.1460-9568.2008.06026.x

Schmalz, G., Widbiller, M., and Galler, K. M. (2017). Signaling Molecules and Pulp Regeneration Gottfried. J. Endod. 43, s7-s11. doi:10.1016/j.joen.2017.06.003

Schmidt, A., Ladage, D., Schinköthe, T., Klausmann, U., Ulrichs, C., Klinz, F.-J., et al. (2006). Basic Fibroblast Growth Factor Controls Migration in Human Mesenchymal Stem Cells. Stem Cells 24, 1750-1758. doi:10.1634/ stemcells.2005-0191

Simon, S. R. J., Berdal, A., Cooper, P. R., Lumley, P. J., Tomson, P. L., and Smith, A. J. (2011). Dentin-Pulp Complex Regeneration. Adv. Dent Res. 23, 340-345. doi:10.1177/0022034511405327

Sjögren, U., Hägglund, B., Sundqvist, G., and Wing, K. (1990). Factors Affecting the Long-Term Results of Endodontic Treatment. J. Endod. 16, 498-504. doi:10.1016/S0099-2399(07)80180-4

Solchaga, L. A., Penick, K., Porter, J. D., Goldberg, V. M., Caplan, A. I., and Welter, J. F. (2005). FGF-2 Enhances the Mitotic and Chondrogenic Potentials of Human Adult Bone Marrow-Derived Mesenchymal Stem Cells. J. Cel. Physiol. 203, 398-409. doi:10.1002/jcp.20238

Srisuwan, T., Tilkorn, D. J., Al-Benna, S., Vashi, A., Penington, A., Messer, H. H., et al. (2012). Survival of Rat Functional Dental Pulp Cells in Vascularized Tissue Engineering chambers. Tissue Cel Survival rat Funct. dental pulp Cell vascularized Tissue Eng. chambers. Tissue Cel. 44, 111-121. doi:10.1016/ j.tice.2011.12.003

Sukarawan, W., Nowwarote, N., Kerdpon, P., Pavasant, P., and Osathanon, T. (2014). Effect of Basic Fibroblast Growth Factor on Pluripotent Marker Expression and colony Forming Unit Capacity of Stem Cells Isolated from Human Exfoliated Deciduous Teeth. Odontology 102, 160-166. doi:10.1007/ s10266-013-0124-3

Suzuki, T., Lee, C. H., Chen, M., Zhao, W., Fu, S. Y., Qi, J. J., et al. (2011). Induced Migration of Dental Pulp Stem Cells for In Vivo Pulp Regeneration. J. Dent Res. 90, 1013-1018. doi:10.1177/0022034511408426

Takedachi, M., Yanagita, M., and Ito, M. (2009). Fibroblast Growth Factor Regulates Cel Funct. Hum. Dental Pulp Cell J. Endod. 35, 1529-1535. doi:10.1016/j.joen.2009.08.010

Takeuchi, N., Hayashi, Y., Murakami, M., Alvarez, F., Horibe, H., Iohara, K., et al. (2015). Similar In Vitro Effects and Pulp Regeneration in Ectopic Tooth Transplantation by Basic Fibroblast Growth Factor and Granulocyte-colony Stimulating Factor. Oral Dis. 21, 113-122. doi:10.1111/odi.12227

Tassi, E., Al-Attar, A., Aigner, A., Swift, M. R., McDonnell, K., Karavanov, A., et al. (2001). Enhancement of Fibroblast Growth Factor (FGF) Activity by an FGFBinding Protein. J. Biol. Chem. 276, 40247-40253. doi:10.1074/jbc.M104933200

Tomson, P. L., Lumley, P. J., Smith, A. J., and Cooper, P. R. (2017). Growth Factor Release from Dentine Matrix by Pulp-Capping Agents Promotes Pulp Tissue Repair-Associated Events. Int. Endod. J. 50, 281-292. doi:10.1111/iej.12624

Torabinejad, M., Parirokh, M., and Dummer, P. M. H. (2018). Mineral Trioxide Aggregate and Other Bioactive Endodontic Cements: an Updated Overview Part II: Other Clinical Applications and Complications. Int. Endod. J. 51, 284-317. doi:10.1111/iej.12843

Trubiani, O., Orsini, G., Zini, N., Di Iorio, D., Piccirilli, M., Piattelli, A., et al. (2008). Regenerative Potential of Human Periodontal Ligament Derived Stem Cells on Three-Dimensional Biomaterials: A Morphological Report. J. Biomed. Mater. Res. 87A, 986-993. doi:10.1002/jbm.a.31837

Tsikandelova, R., Mladenov, P., Planchon, S., Kalenderova, S., Praskova, M., Mihaylova, Z., et al. (2018). Proteome Response of Dental Pulp Cells to Exogenous FGF8. J. Proteomics 183, 14-24. doi:10.1016/j.jprot.2018.05.004

Tsuboi, T., Mizutani, S., Nakano, M., Hirukawa, K., and Togari, A. (2003). FGF-2 Regulates Enamel and Dentine Formation in Mouse Tooth Germ. Calcified Tissue Int. 73, 496-501. doi:10.1007/s00223-002-4070-2

Tsutsumi, S., Shimazu, A., Miyazaki, K., Pan, H., Koike, C., Yoshida, E., et al. (2001). Retention of Multilineage Differentiation Potential of Mesenchymal Cells during Proliferation in Response to FGF. Biochem. Biophysical Res. Commun. 288, 413-419. doi:10.1006/bbrc.2001.5777

Vaseenon, S., Chattipakorn, N., and Chattipakorn, S. C. (2020). The Possible Role of Basic Fibroblast Growth Factor in Dental Pulp. Arch. Oral Biol. 109, 104574. doi:10.1016/j.archoralbio.2019.104574 
Vining, K. H., Mooney, D. J., Mina, M., Vijaykumar, A., and Kalajzic, I. (2018). FGF2 Enhances Odontoblast Differentiation by aSMA ${ }^{+}$Progenitors In Vivo. J. Dent Res. 97, 1170-1177. doi:10.1177/0022034518769827

Wang, D.-R., Wang, Y.-H., Pan, J., Tian, W.-D., Key, S., and Disease, O. (2020). Neurotrophic Effects of Dental Pulp Stem Cells in Repair of Peripheral Nerve after Crush Injury. Wjsc 12, 1196-1213. doi:10.4252/wjsc.v12.i10.1196

Wang, D., Wang, Y., Tian, W., and Pan, J. (2019a). Advances of Tooth - Derived Stem Cells in Neural Diseases Treatments and Nerve Tissue Regeneration. Cel Prolif 52, e12572. doi:10.1111/cpr.12572

Wang, J., Liu, S., Li, J., and Yi, Z. (2019b). The Role of the Fibroblast Growth Factor Family in Bone-related Diseases. Chem. Biol. Drug Des. 94, 1740-1749. doi:10.1111/cbdd.13588

Wigler, R., Kaufman, A. Y., Lin, S., Steinbock, N., Hazan-Molina, H., and Torneck, C. D. (2013). Revascularization: A Treatment for Permanent Teeth with Necrotic Pulp and Incomplete Root Development. J. Endodontics 39, 319-326. doi:10.1016/j.joen.2012.11.014

Wu, J., Huang, G. T.-J., He, W., Wang, P., Tong, Z., Jia, Q., et al. (2012). Basic Fibroblast Growth Factor Enhances Stemness of Human Stem Cells from the Apical Papilla. J. Endodontics 38, 614-622. doi:10.1016/j.joen.2012.01.014

Yamamura, T. (1985). Differentiation of Pulpal Cells and Inductive Influences of Various Matrices with Reference to Pulpal Wound Healing. J. Dent Res. 64, 530-540. doi:10.1177/002203458506400406

Yang, J.-w., Zhang, Y.-f., Sun, Z.-y., Song, G.-t., and Chen, Z. (2015). Dental Pulp Tissue Engineering with bFGF-Incorporated Silk Fibroin Scaffolds. J. Biomater. Appl. 30, 221-229. doi:10.1177/0885328215577296

Yang, J., Yuan, G., and Chen, Z. (2016). Pulp Regeneration: Current Approaches and Future Challenges. Front. Physiol. 7, 1-8. doi:10.3389/fphys.2016.00058

Ye, Q., Wu, Y., Wu, J., Zou, S., Al-Zaazaai, A. A., Zhang, H., et al. (2018). Neural Stem Cells Expressing bFGF Reduce Brain Damage and Restore Sensorimotor Function after Neonatal Hypoxia-Ischemia. Cell Physiol Biochem 45, 108-118. doi:10.1159/000486226

Yeoh, J. S. G., and de Haan, G. (2007). Fibroblast Growth Factors as Regulators of Stem Cell Self-Renewal and Aging. Mech. Ageing Dev. 128, 17-24. doi:10.1016/ j.mad.2006.11.005

Yuan, X., Cao, X., and Yang, S. (2019b). IFT80 Is Required for Stem Cell Proliferation, Differentiation, and Odontoblast Polarization during Tooth Development. Cell Death Dis. 10, 63. doi:10.1038/s41419-018-0951-9

Yuan, X., Liu, M., Cao, X., and Yang, S. (2019a). Ciliary IFT80 Regulates Dental Pulp Stem Cells Differentiation by FGF/FGFR1 and Hh/BMP2 Signaling. Int. J. Biol. Sci. 15, 2087-2099. doi:10.7150/ijbs.27231
Zbinden, A., Browne, S., Altiok, E. I., Svedlund, F. L., Jackson, W. M., and Healy, K E. (2018). Multivalent Conjugates of Basic Fibroblast Growth Factor Enhance In Vitro Proliferation and Migration of Endothelial Cells. Biomater. Sci. 6, 1076-1083. doi:10.1039/c7bm01052d

Zhang, C., Chen, J., Feng, C., Shao, X., Liu, Q., Zhang, Q., et al. (2014). Intranasal Nanoparticles of Basic Fibroblast Growth Factor for Brain Delivery to Treat Alzheimer's Disease. Int. J. Pharmaceutics 461, 192-202. doi:10.1016/ j.ijpharm.2013.11.049

Zhang, J., Lian, M., Cao, P., Bao, G., Xu, G., Sun, Y., et al. (2017). Effects of Nerve Growth Factor and Basic Fibroblast Growth Factor Promote Human Dental Pulp Stem Cells to Neural Differentiation. Neurochem. Res. 42, 1015-1025. doi:10.1007/s11064-016-2134-3

Zhang, R., Xie, L., Wu, H., Yang, T., Zhang, Q., Tian, Y., et al. (2020). Alginate/ laponite Hydrogel Microspheres Co-encapsulating Dental Pulp Stem Cells and VEGF for Endodontic Regeneration. Acta Biomater. 113, 305-316. doi:10.1016/ j.actbio.2020.07.012

Zhang, R., Zhang, M., Li, C., Wang, P., Chen, F., and Wang, Q. (2013). Effects of Basic Fibroblast Growth Factor and Vascular Endothelial Growth Factor on Proliferation,migration and Adhension of Human Periodontal Ligament Stem Cells In Vitro. Chinise 48, 278-284. doi:10.3760/cma.j.issn.10020098.2013.05.006

Zheng, K., Feng, G., Zhang, J., Xing, J., Huang, D., Lian, M., et al. (2020). Basic Fibroblast Growth Factor Promotes Human Dental Pulp Stem Cells Cultured in 3D Porous Chitosan Scaffolds to Neural Differentiation. Int. J. Neurosci. 131, 625-633. doi:10.1080/ 00207454.2020 .1744592

Zhou, Y., Wang, Z., Li, J., Li, X., and Xiao, J. (2018). Fibroblast Growth Factors in the Management of Spinal Cord Injury. J. Cel. Mol. Med. 22, 25-37. doi: $10.1111 /$ jcmm.13353

Conflict of Interest: The authors declare that the research was conducted in the absence of any commercial or financial relationships that could be construed as a potential conflict of interest.

Copyright (c) $2021 \mathrm{Liu}, \mathrm{Yu}, \mathrm{Ye}$ and Gao. This is an open-access article distributed under the terms of the Creative Commons Attribution License (CC BY). The use, distribution or reproduction in other forums is permitted, provided the original author(s) and the copyright owner(s) are credited and that the original publication in this journal is cited, in accordance with accepted academic practice. No use, distribution or reproduction is permitted which does not comply with these terms. 